\title{
Cohort Profile: The Christchurch IBS cOhort to investigate Mechanisms FOr gut Relief and improved Transit (COMFORT)
}

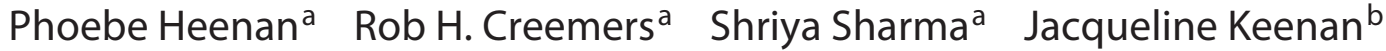 \\ Simone Bayer ${ }^{a}$ Wayne Young ${ }^{c-e}$ Janine Cooney ${ }^{e, f}$ Kelly Armstrong ${ }^{c}$ \\ Karl Fraser ${ }^{\mathrm{c}-\mathrm{e}}$ Paula M. Skidmore ${ }^{\mathrm{a}}$ Nicholas J. Talley ${ }^{g} \quad$ Nicole Roy $^{\mathrm{d}} \mathrm{e}, \mathrm{h}$ \\ Richard B. Gearry a, e COMFORT Cohort Collaborators \\ aDepartment of Medicine, University of Otago, Christchurch, New Zealand; 'bepartment of Surgery, \\ University of Otago, Christchurch, New Zealand; ${ }^{C}$ Food Nutrition and Health, Grasslands Research Centre, \\ AgResearch, Palmerston North, New Zealand; ${ }^{d}$ Riddet Institute, Massey University, Palmerston North, New Zealand; \\ eHigh Value Nutrition Science Challenge, University of Newcastle, Newcastle, NSW, Australia; 'Massey University, \\ Biological Chemistry \& Bioactives Group and Food Innovation, Palmerston North, New Zealand; gPlant \& Food \\ Research, Research and Innovation Division, Hamilton, New Zealand; hepartment of Human Nutrition, \\ University of Otago, Dunedin, New Zealand
}

\section{Keywords}

Irritable bowel syndrome · Functional gastrointestinal disorders · Cohort profile · Observational study · Case control study

\begin{abstract}
Background and aims: This cross-sectional observational case-control study was initiated in July 2016 with the aim of increasing an understanding of the underlying disease mechanisms in functional gastrointestinal disorders (FGIDs) including irritable bowel syndrome (IBS), functional diarrhoea (FD), and functional constipation (FC). Specific areas of interest include the effect of food, microbiome, host and microbial genetics, metabolome, and psychological variables on unexplained chronic gastrointestinal (GI) symptoms. Methods: This study recruited consecutive patients
\end{abstract}

\begin{tabular}{ll}
\hline karger@karger.com & (c) 2020 The Author(s) \\
Published by S. Karger AG, Basel & Karger \\
Thw.karger.com/iid & This article is licensed under the Creative Commons Attribution- \\
NonCommercial-NoDerivatives 4.0 International License (CC BY- \\
NC-ND) (http://www.karger.com/Services/OpenAccessLicense). \\
Usage and distribution for commercial purposes as well as any dis- \\
tribution of modified material requires written permission.
\end{tabular}

who were attending one of two endoscopy centres in Christchurch, New Zealand, for colonoscopy and a subgroup of participants from the general public who did not undergo colonoscopy. Participants with known GI disease other than an FGID were excluded. Those with symptoms were recruited as cases, whilst those without symptoms were recruited as controls. In the days prior to preparation for colonoscopy, or an agreeable time for those not undergoing colonoscopy, demographic, symptom, psychological, dietary, and health data were collected in addition to biological samples

COMFORT Cohort Collaborators: Dr. Teresa Chalmers-Watson, Dr. James Falvey, Dr. Michael Burt, Associate Professor Catherine Stedman, Professor Frank Frizelle, Dr. Bruce Chapman, Mr. John Frye, Dr. Steven Ding, Dr. Gary Lim, Associate Professor Tim Eglinton, Mr. Ross Roberts, Dr. Alison Ross, Professor Murray Barclay, Mr. Chris Wakeman. 
(breath, faeces, blood, and urine). Colonic biopsies were taken at the time of colonoscopy from participants in the colonoscopy subgroup. Results: Between July 2016 and December 2018, 349 participants were recruited, 315 of whom completed the study, 220 participants were from the colonoscopy subgroup, and 95 from the non-colonoscopy subgroup. This included 129 controls and 186 cases (57 IBS-diarrhoea predominant, 30 IBS-constipation predominant, 41 IBS-mixed, 42 FC, and 16 FD). The mean age of FGID cases was 53.4 years and controls 54.4 years. Cases (149/186, $80.1 \%)$ and controls $(57 / 72,55.8 \%)$ were predominantly female. Education levels were similar across the cohort. Smoking and alcohol rates were also similar. Biological samples were collected as planned from participants. Conclusions: The COMFORT cohort is a unique clinical cohort of FGID cases and controls with a wide range of demographic, dietary, clinical, psychological, and health data in addition to biological samples. Future research will aim to use a systems biology approach to establish the potential role of diet, host-microbiome interactions, and other factors in the pathogenesis of FGIDs.

(c) 2020 The Author(s)

Published by S. Karger AG, Basel

\section{Introduction}

In clinical practice, patients commonly consult with unexplained chronic gastrointestinal (GI) symptoms referred to as functional gastrointestinal disorders (FGIDs); in these conditions, no obvious physical cause is identified on routine testing [1]. One of the most common FGIDs is the irritable bowel syndrome (IBS), which is associated with significant health care costs and decreased quality of life [2] and is also one of the most common causes of visits to primary care physicians and gastroenterologists [2-4]. IBS predominantly affects women and is often diagnosed in those aged 35 years or younger [5, $6]$. While prevalence differs between countries, IBS global prevalence is estimated to be $11 \%$ [7].

IBS is characterised by recurrent abdominal pain associated with a change in the frequency and/or form of bowel motions in the absence of a known organic cause [1]. These symptoms exist on a spectrum, with IBS being subtyped into constipation-, diarrhoea-, or mixed phenotype-predominant (IBS-C, IBS-D, and IBS-M, respectively), depending on the frequency and form of individual patients' bowel motions $[1,8]$. Currently, there are no reliable biomarkers for the diagnosis of IBS [9]; the current "gold standard" diagnostic framework, the Rome IV criteria, uses the presence of GI symptoms typical of
IBS in the absence of organic disease as a basis for diagnosis [1].

Current scientific consensus has led to the definition of IBS (and other FGIDs) as a dysregulation of the braingut axis (BGA) [10]. However, the aetiology of IBS is complex and ultimately unknown. Multiple biological systems have been implicated in IBS pathophysiology [11]: differences have been discovered between IBS patients and healthy controls in inflammation pathways, the immune system, the GI epithelial barrier, the GI microbiota, the hypothalamic-pituitary-adrenal axis, cognitive areas of the central nervous system, and the enteric nervous system [12]. These differences have been presumed to lead to the manifestation of classical IBS symptoms such as visceral hypersensitivity (linked to recurrent abdominal pain) and altered GI motility [1319].

\section{Rationale for the Study}

Due to the heterogeneous presentation of IBS symptoms between patients and sometimes within the same patient over time, treatments for IBS have historically been less than satisfactory. These have included lifestyle changes, fibre supplementation, behavioural therapy, antidepressants, and antispasmodics [20-23]. While these treatments may reduce IBS symptoms in some patients, at present there is no known cure for IBS, frustrating clinicians and patients alike.

Research into the aetiology of IBS has traditionally focused on only one or two potential aspects of pathogenesis; however, due to recent technological advances, researchers are increasingly moving towards a systems biology approach to addressing the potential multifactorial aetiology of this disorder [24]. As such, the Christchurch IBS cOhort to investigate Mechanisms FOr gut Relief and improved Transit (COMFORT) study was designed to capture and integrate a wide range of biological, clinical, demographic, psychological, and dietary data in order to study the pathophysiology of IBS. As a prospective observational case control study, the COMFORT study aims to (1) develop a novel cohort specifically designed to investigate a wide range of variables and their effect on IBS pathogenesis, activity, and prognosis, (2) develop dietary profiles for those with correlations to IBS symptomology in those with and without IBS, (3) correlate and integrate these dietary data with biological, clinical, and psychological variables, and (4) develop a data repository of biological specimens that will allow for prospective in vitro and ex vivo experiments for novel food-based interventions in IBS. 


\section{IBS}

\section{Abdominal pain}

a) More than once a week

b) Associated with change in frequency and/or form of stools

\begin{tabular}{|c|c|c|c|}
\hline IBS-D & IBS-C & IBS-M & IBS-U \\
\hline $\begin{array}{l}\text { 1. }>25 \% \text { stools } \\
\text { Bristol stool } \\
\text { chart } 6-7\end{array}$ & $\begin{array}{l}\text { 1. }>25 \% \text { stools } \\
\text { Bristol stool } \\
\text { chart } 1-2\end{array}$ & $\begin{array}{l}\text { 1. }>25 \% \text { stools } \\
\text { Bristol stool } \\
\text { chart } 1-2\end{array}$ & $\begin{array}{l}\text { 1. Meet diagnostic } \\
\text { criteria for IBS }\end{array}$ \\
\hline $\begin{array}{l}\text { 2. }<25 \% \text { stools } \\
\text { Bristol stool } \\
\text { chart } 1-2\end{array}$ & $\begin{array}{l}\text { 2. }<25 \% \text { stools } \\
\text { Bristol stool } \\
\text { chart 6-7 }\end{array}$ & $\begin{array}{l}\text { 2. }>25 \% \text { stools } \\
\text { Bristol stool } \\
\text { chart 6-7 }\end{array}$ & $\begin{array}{l}\text { 2. Stool cannot be } \\
\text { classified into } \\
\text { IBS-D, IBS-C, or } \\
\text { IBS-M }\end{array}$ \\
\hline
\end{tabular}

\section{Other FGID}

1. Symptomatc

2. Do not meet the criteria for IBS

1. Criteria fulfilled for the last 3 months

2. Symptoms onset more than 6 months prior

Fig. 1. Summary of the Rome IV diagnostic criteria.

\section{Methods}

Setting, Location, and Relevant Data

Participants who were undergoing colonoscopy at one of two endoscopy units in Christchurch, New Zealand, were referred by their treating physician prior to their procedure (colonoscopy subgroup). Other potential participants who responded to advertisements and were not undergoing colonoscopy were also recruited (non-colonoscopy subgroup). Potential participants were contacted by a member of the research team with further information about participation in the study. The eligibility of participants (1870 years inclusive) was assessed by the research team, using the Rome IV criteria (summarised in Fig. 1) [1], which was used to diagnose bowel disorder (IBS, functional diarrhoea [FD], or functional constipation [FC]) cases. The presence of other FGIDs was not assessed. Prospective participants with "red flag" symptoms indicative of organic disease including blood in the stool, nocturnal symptoms, unexplained weight loss, and anaemia were excluded from the study, as were participants who had a history of GI diseases or abdominal surgery, pregnancy, or were unable to give informed consent. Participants undergoing colonoscopy were also excluded if significant organic bowel disease was discovered. Participants who did not meet exclusion criteria and who had no significant GI symptoms (functional or otherwise) were enrolled in the study as controls. Controls from the colonoscopy subgroup were participants who were undergoing colonoscopy but did not have GI symptoms or a history of an underlying significant health problem including GI disease. Many of these controls may have had a past history or family history of sporadic polyps or colorectal cancer, respectively, and were undergoing surveillance, but patients with familial polyposis syndromes were excluded. Eligible patients were enrolled in the study, and written informed consent was obtained from each participant to participate in the study prior to any study procedures being undertaken.

\section{Collection and Processing of Samples and Data}

Once written informed consent was obtained, an electronic case report form (eCRF) was generated for each participant, who was de-identified and given a unique 5 digit ID number. These, and all other information pertaining to participants, were stored physically or electronically according to ethical requirements. The research team organized the start date of the study individually with each participant to optimize the completion of questionnaires, the efficient return of biological samples, and the close timing of data and sample collection in those who underwent colonoscopy. Questionnaires and biological sample collection equipment were labelled with the participants' 5-digit ID number and posted to the participant. The dietary data collection and questionnaires were completed over 3 days (Fig. 2). For those participants who were undergoing colonoscopy, all data and biological samples except colonic mucosal biopsies were collected before the commencement of bowel preparation (no later than $48 \mathrm{~h}$ prior to colonoscopy).

A wide range of variables were collected as part of the COMFORT cohort study procedures (Fig. 3). Biological samples collected included breath, blood, faeces, urine, and colonic biopsy tissue. A range of questionnaires were used to collect many clinical, demographic, and psychological variables. The Modified Hunter New England Survey [25] included Rome IV questionnaires [26] to classify participants as controls, cases, and sub-phenotypes, Short Form-12 for quality of life [27], medical history questions, and demographics, and the Hospital Anxiety and Depression Scale (HADS) [28]. The validated Structured Assessment of Gastrointestinal Symptoms (SAGIS) [29] evaluated a wide range of GI symptoms. The Economic Standard of Living Index-short form (ELSI-sf) [30] is a validated comprehensive measure of living standard in New Zealand. The Patient-Reported Outcomes Measurement Information System (PROMIS ${ }^{\circledR}$ ) [31-33] tools for GI symptoms and emotional distress are validated tools for measuring 


\begin{tabular}{|c|c|c|c|c|c|c|c|}
\hline & & $\begin{array}{l}\text { Pre- } \\
\text { enrolment }\end{array}$ & Day $1^{2}$ & Day $2^{2}$ & Day $3^{2}$ & Day $4^{3}$ & Colonoscopy ${ }^{4}$ \\
\hline \multirow{2}{*}{ Recruitment } & Advertisements & $x$ & & & & & \\
\hline & $\begin{array}{l}\text { Referral from } \\
\text { Gastroenterologist }\end{array}$ & $x$ & & & & & \\
\hline \multicolumn{2}{|c|}{$\begin{array}{c}\text { Written informed consent from willing } \\
\text { participants }\end{array}$} & $x$ & & & & & \\
\hline \multirow{5}{*}{$\begin{array}{l}\text { Modified hunter } \\
\text { New England } \\
\text { survey } \\
\text { (ModHNES) }\end{array}$} & Rome IV & & \multirow{5}{*}{$x$} & & & & \\
\hline & SF-12 & & & & & & \\
\hline & Medical history & & & & & & \\
\hline & $\begin{array}{l}\text { Hospital anxiety and } \\
\text { depression scale (HADS) }\end{array}$ & & & & & & \\
\hline & Demographics & & & & & & \\
\hline \multicolumn{2}{|c|}{$\begin{array}{c}\text { Structured assessment of gastrointestinal } \\
\text { symptoms (SAGIS) }\end{array}$} & & $x$ & & & & \\
\hline \multicolumn{2}{|c|}{$\begin{array}{l}\text { Econimic living standards indes - short form } \\
\text { (ELSI-sf) }\end{array}$} & & $x$ & & & & \\
\hline \multicolumn{2}{|c|}{$\begin{array}{l}\text { Patient reported outcomes measurement } \\
\text { information system - gastrointestinal } \\
\text { (PROMIS-GI) }\end{array}$} & & & & $x$ & & \\
\hline \multicolumn{2}{|c|}{ PROMIS-emotional distress } & & & & $x$ & & \\
\hline \multicolumn{2}{|c|}{ Food and symptoms times (FAST) diary } & & $x$ & $x$ & $x$ & & \\
\hline \multicolumn{2}{|c|}{ Stool sample collection } & & & & & $x$ & \\
\hline \multicolumn{2}{|c|}{ Urine sample collection } & & & & & $x$ & \\
\hline \multicolumn{2}{|c|}{ Blood sample collection } & & & & & $x$ & \\
\hline \multicolumn{2}{|c|}{ Breath sample collection } & & & & & $x$ & \\
\hline \multicolumn{2}{|c|}{ Colonic mucosa sample collection } & & & & & & $x$ \\
\hline
\end{tabular}

Fig. 2. Schedule of COMFORT cohort variables and visits. ${ }^{1} \mathrm{Re}-$ cruitment and informed consent was obtained from participants prior to their enrolment in the COMFORT study; subsequently, all paperwork and sample collection packs were delivered to the participant for completion at home. ${ }^{2}$ Day 1 of the study was the day participants commenced the FAST diary and completed the MODHNES, SAGIS, and ELSI-sf; the FAST diary was also filled

these outcomes and can be compared to population norms. The Food and Symptom Times (FAST [34]) diary is a validated 3-day weighted food diary, which records all aspects of participants' diets and GI symptoms contemporaneously. This allows for temporal relationships between food and symptoms to be explored.

Stool and urine samples were collected on the last day of the FAST diary at participants' homes into $60 \mathrm{~mL}$ specimen containers provided to participants (Fig. 2). Samples were kept at $4^{\circ} \mathrm{C}$ and delivered to the research team within $24 \mathrm{~h}$ of collection at which time $58 \mathrm{~mL}$ of blood and $3 \mathrm{~L}$ of breath were obtained from the participant. Samples were initially processed at the University of Otago, Christchurch; volatile metabolites were extracted from the breath out on day 2 and day 3 . The PROMIS-GI and PROMIS-emotional distress were also completed on day $3 .{ }^{3}$ On day 4 of the study, the participants collected their stool and urine sample at home and then met with the study team in order to collect blood and breath samples. Days 1-4 were consecutive days. ${ }^{4}$ Colonic mucosa biopsies were collected during colonoscopy (in the colonoscopy subgroup only).

samples onto a carbon trap within an hour of collection and stored sealed at $4^{\circ} \mathrm{C}$. Stool and urine samples were kept at $4^{\circ} \mathrm{C}$ until they were sorted into $1 \mathrm{~g}$ aliquots and then snap frozen with liquid nitrogen within $24 \mathrm{~h}$ of collection. Eighteen millilitres of lithium heparin ( $\mathrm{LiH})$-treated blood, $12 \mathrm{~mL}$ of ethylenediaminetetraacetic acid-treated blood, and $10 \mathrm{~mL}$ of untreated blood were centrifuged at 2,000 $\mathrm{g}$, and plasma was distributed into $0.5 \mathrm{~mL}$ aliquots and stored at $-80^{\circ} \mathrm{C}$. Peripheral blood mononuclear cells (PBMCs) were extracted from the remaining $18 \mathrm{~mL}$ of $\mathrm{LiH}$-treated blood, two-thirds of which were stored in RNA cell protect at $-80^{\circ} \mathrm{C}$ and the last third in a solution of $90 \%$ foetal bovine serum in the gaseous phase of liquid nitrogen $[35,36]$. In those participants who 


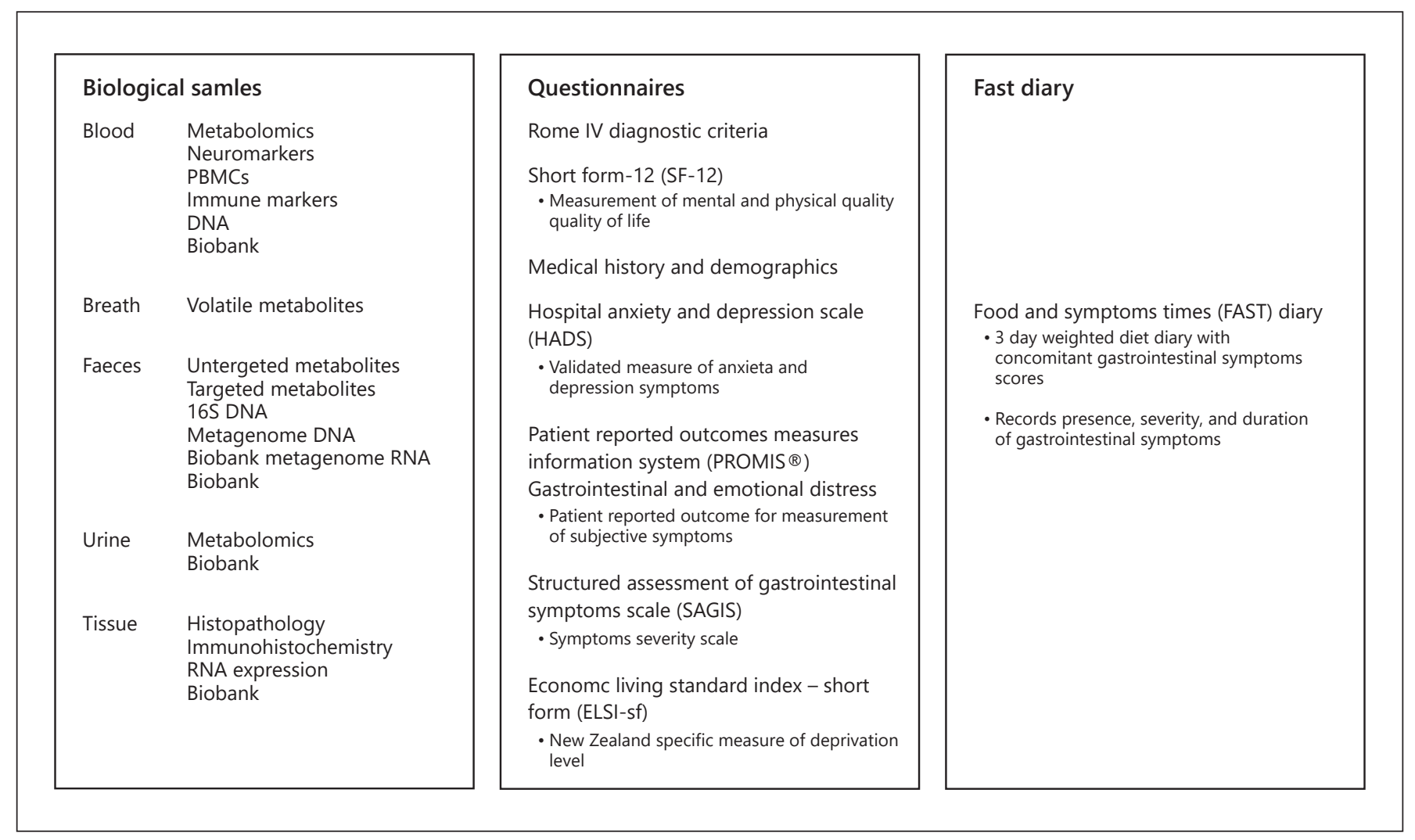

Fig. 3. Biological samples and intended experiments, questionnaires and diet diary completed by each participant enrolled in the COMFORT study.

underwent colonoscopy and in those who consented for biopsies to be taken for research purposes, 8 colonic mucosa samples were collected from participants undergoing colonoscopy, four from the right colon and four from the left colon. Two biopsies from each side of the colon were stored in RNAlater ${ }^{\circledR}$ at $-80^{\circ} \mathrm{C}$, and the rest of the biopsies were fixed in formalin and then embedded in paraffin blocks.

\section{Results}

Recruitment began in July 2016 at the Christchurch Public Hospital gastroenterology day ward and at the Southern Cross Hospital Southern Endoscopy Centre in Christchurch, New Zealand. An amendment to ethical approval was sought and approved in August 2017, which granted the ability to recruit participants from the general population without colonic mucosa biopsy collection. 1,341 people were either invited to be a part of the study or expressed interest in participating; this included 392 people from the general public, 740 people undergoing colonoscopy at Christchurch Public Hospital and 209 people undergoing colonoscopy at Southern Cross Hospital. A total of 349 participants were enrolled before December 21, 2018, 253 from either Christchurch Public Hospital or Southern Cross Hospital, and 96 from the general public (this group did not undergo colonoscopy, but provided all other biological samples). Twenty participants either subsequently declared their unwillingness to participate in the study after initially consenting $(15 / 20)$ or were withdrawn from the study as a result of findings from colonoscopy (5/20, summarised in Fig. 4). In a study of this size, over a period of this time, not all participants were able to provide all questionnaire data or biological samples as planned. There were a range of reasons for this incomplete dataset including unwillingness to provide some biological samples, lost to follow-up, or technical issues around specimen collection. Therefore, the number of participants who completed each data point and provided biological samples is less than the total number of participants in the study (Fig. 4; Table 1). In addition, colonic biopsies were obviously not available for participants who did not undergo colonoscopy (95). Partici- 


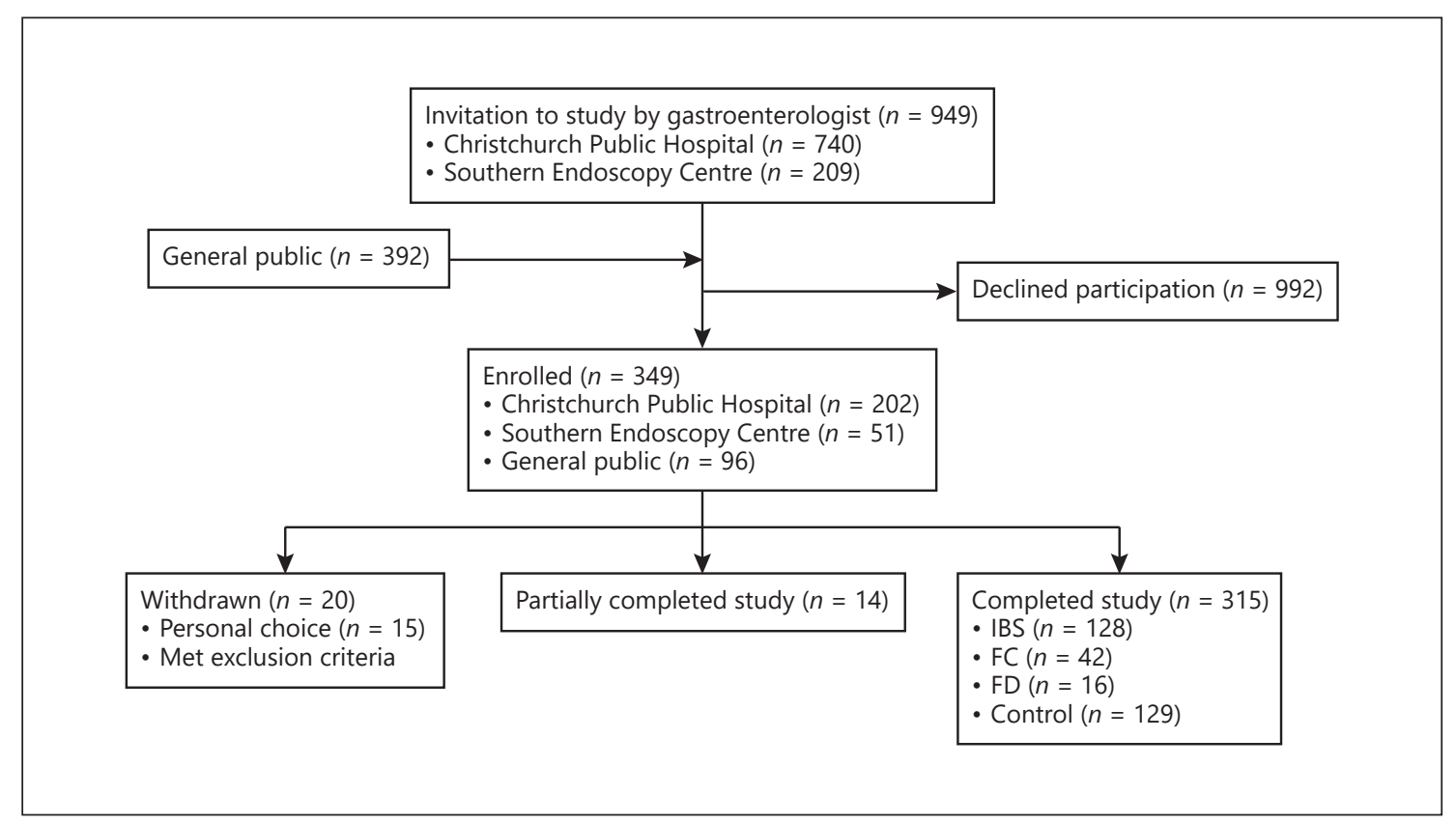

Fig. 4. Flow diagram showing overview of the patients recruited for the COMFORT study.

pants were identified as a case (IBS, FC, or FD) or as a control using the Rome IV criteria based on the responses provided by participants in the Modified Hunter New England Survey (MODHNES) questionnaire, 128 participants met the criteria for IBS, 42 met the criteria for FC, and 16 met the criteria for FD (Table 2). There was no significant difference in the diagnostic sub-groups between patients recruited from hospital and the general public ( $p=0.35$; Table 3 ).

The baseline characteristics of the COMFORT cohort are summarised in Table 2. The mean age of the study participants was $53.4 \pm 12.4$ years, with a significant difference found between the mean age of those with IBS-M and FC (49.73 \pm 13.9 and $57.74 \pm 10.5$; $p=0.046)$; otherwise, the ages of the case groups were not statistically different. However, there was a significant difference between the average ages of the participants recruited in hospital $(55.7 \pm 10.3)$ and those from the general public $(47.8 \pm 1.8, p \leq 0.01$, summarised in Table 3$)$. There was a female predominance in the cohort (70\% female) and in every sub-phenotype group. The mean economic standard of living among the COMFORT cohort was 35.7 (corresponding to the level "comfortable") with no significant difference between the sub-phenotype groups $(p=0.60)$. There was no statistically significant difference in education level $(p=0.31)$, alcohol consumption $(p=$ 0.90 ), smoking status ( $p=0.73$ for current smoking and $p=0.27$ for having ever smoked), exercise ( $p=0.91$ for walking, $p=0.68$ for moderate exercise, and $p=0.27$ for vigorous exercise), or metabolic equivalent to tasks (METs, $p=0.07$ ) between the different diagnosis groups. METs were calculated in accordance with the Australian Bureau of Statistics National Health Survey: Users' Guide [37]. There were significant differences found between the populations of participants recruited from hospital and those recruited from the general public in having ever smoked ( $p \leq 0.01$; Table 3$)$, alcohol consumption ( $p=$ $0.01)$, and education $(p=0.001) .252$ participants were born in New Zealand (80\%), 2\% reported themselves as being of Māori descent.

Participants who completed the study provided blood, breath, stool, and urine samples where possible; participants were not excluded from the study if they were unable or unwilling to provide the entirety of these samples. Overall $87.5 \%$ of stool samples, $90.6 \%$ of urine samples, $93.0 \%$ of breath samples, $82.4 \%$ serum, and $71.4 \%$ of PBMC samples were supplied by participants (Table 1); there was no statistically significant difference in the rates of sample collection between the different diagnosis types. However, more serum and PBMC and urine samples were taken from participants recruited from the general public ( $p \leq 0.05) .190 / 253(75.1 \%)$ of participants undergoing colonoscopy provided colonic mucosal biopsies, this was $60.3 \%$ of the total cohort. 
Table 1. Numbers and percentages of biological samples collected from participants in the COMFORT study

\begin{tabular}{|c|c|c|c|c|c|c|c|c|c|c|}
\hline Stool, $n(\%)$ & $53(93.0 \%)$ & $25(83.3 \%)$ & $35(85.4 \%)$ & $113(88.3 \%)$ & $38(90.5 \%)$ & $15(93.8 \%)$ & $53(91.4 \%)$ & $166(89.2 \%)$ & $121(93.8 \%)$ & 0.65 \\
\hline Urine, $n(\%)$ & $54(94.7 \%)$ & $27(90.0 \%)$ & $37(90.2 \%)$ & $118(92.2 \%)$ & $38(90.5 \%)$ & $16(100 \%)$ & $54(93.1 \%)$ & $172(92.5 \%)$ & $111(86.0 \%)$ & 0.71 \\
\hline Serum, $n(\%)$ & $48(84.2 \%)$ & $25(83.3 \%)$ & $33(80.5 \%)$ & $106(82.8 \%)$ & $34(81.0 \%)$ & $13(81.3 \%)$ & 47 (81.0\%) & $153(82.2 \%)$ & $99(76.7 \%)$ & 0.95 \\
\hline Tissue, $n(\%)$ & $38(66.7 \%)$ & $17(56.7 \%)$ & $26(63.4 \%)$ & $81(63.3 \%)$ & $27(64.3 \%)$ & $9(56.3 \%)$ & $36(62.1 \%)$ & 117 (62.9\%) & $73(56.6 \%)$ & 0.79 \\
\hline
\end{tabular}

PMBC, peripheral blood mononuclear cell; FGIDs, functional gastrointestinal disorder; FC, functional constipation; FD, functional diarrhoea; IBS-D, irritable bowel syndrome-diarrhoea predominant; IBS-C, irritable bowel syndrome-constipation predominant; IBS-M, irritable bowel syndrome-mixed phenotype predominant.

Table 2. Baseline characteristics of the COMFORT study participants

\begin{tabular}{|c|c|c|c|c|c|c|c|c|}
\hline & \multicolumn{4}{|l|}{ IBS } & \multicolumn{3}{|l|}{ Other FGIDs } & Controls \\
\hline Male/female & $13 / 44$ & $2 / 28$ & $7 / 34$ & $22 / 106$ & $12 / 30$ & $3 / 13$ & $15 / 43$ & $57 / 72$ \\
\hline Average age $\pm S D$, years & $52.8 \pm 12$ & $51.1 \pm 14$ & $49.7 \pm 13$ & $51.5 \pm 13$ & $57.7 \pm 10$ & $57.8 \pm 10$ & $57.7 \pm 10$ & $54.4 \pm 16$ \\
\hline \multicolumn{9}{|l|}{ Education level achieved } \\
\hline Tertiary & $11(28.9 \%)$ & $15(51.7 \%)$ & $17(48.6 \%)$ & $43(42.2 \%)$ & $15(36.6 \%)$ & $7(46.7 \%)$ & $22(39.3 \%)$ & $59(47.2 \%)$ \\
\hline Secondary & $11(28.9 \%)$ & $4(13.8 \%)$ & $4(11.4 \%)$ & $19(18.6 \%)$ & $11(26.8 \%)$ & $2(13.3 \%)$ & $13(23.2 \%)$ & $15(12.0 \%)$ \\
\hline Primary & $9(23.7 \%)$ & $6(20.7 \%)$ & $7(20.0 \%)$ & $22(21.6 \%)$ & $6(14.6 \%)$ & $1(6.7 \%)$ & $7(12.5 \%)$ & $14(11.2 \%)$ \\
\hline Currently drink alcohol & $44(80.0 \%)$ & $23(74.2 \%)$ & $33(80.5 \%)$ & $100(78.7 \%)$ & $34(81.0 \%)$ & $12(85.7 \%)$ & $46(82.1 \%)$ & $102(79.1 \%)$ \\
\hline Currently smoking & $2(7.7 \%)$ & $2(15.4 \%)$ & $1(6.3 \%)$ & $5(3.9 \%)$ & $1(7.1 \%)$ & $2(33.3 \%)$ & $3(5.4 \%)$ & $5(12.2 \%)$ \\
\hline Past smoking & $26(46.4 \%)$ & $13(43.3 \%)$ & $16(39.0 \%)$ & $55(43.3 \%)$ & $14(3.3 \%)$ & $6(42.9 \%)$ & $20(35.7)$ & $41(31.8 \%)$ \\
\hline Average MET & $18,620.7$ & $42,114.3$ & $26,733.6$ & $26,725.6$ & $12,545.5$ & $28,294.8$ & $23,950.1$ & $29,586.8$ \\
\hline
\end{tabular}

FGIDs, functional gastrointestinal disorders; FC, functional constipation; FD, functional diarrhoea; IBS-D, irritable bowel syndrome-diarrhoea predominant; IBS-C, irritable bowel syndrome-constipation predominant; IBS-M, irritable bowel syndrome-mixed phenotype predominant; MET, metabolic equivalent to tasks.

\section{Discussion}

IBS is a major worldwide health problem and is associated with decreased quality of life and significant direct and indirect health care costs $[2,38]$. Due to the inherent heterogeneity of IBS, as well as the variety of diagnostic criteria and methodology used, the aetiology and pathophysiology of IBS have remained poorly defined [39]. The COMFORT study was designed to collect, integrate, and interrogate a variety of pathophysiological data from IBS, FC, and FD cases and compare these to healthy controls to better understand FGID pathogenesis. A systems biology approach will be used to integrate these data in addition to those generated from analysis of the biological samples using a range of platforms. Within the study period, 186 participants met the criteria for FGID cases, and 129 healthy controls. Within the case group, 128 participants met the criteria for IBS (40.6\% of the total cohort). 
Table 3. Similarities and differences between participants recruited from hospital gastroenterology lists and the general public

\begin{tabular}{|c|c|c|c|c|c|}
\hline$N$ & 169 & 51 & 220 & 95 & 0.3 \\
\hline Female/male & $107 / 62$ & $35 / 16$ & $142 / 78$ & $79 / 16$ & $\leq 0.01$ \\
\hline Average age $\pm \mathrm{SD}$, years & $56.0 \pm 10.4$ & $54.7 \pm 9.9$ & $55.7 \pm 10.3$ & $47.8 \pm 14.8$ & $\leq 0.01$ \\
\hline ELSI-sf living standard score & 34.9 & 36.1 & 35.2 & 36.8 & 0.3 \\
\hline Education (Bachelor's degree or higher, \%) & $78(46)$ & $20(39.2)$ & $98(44.5)$ & $56(59.6)$ & $\leq 0.01$ \\
\hline Average MET & $25,849.9$ & $30,548.7$ & $28,199.3$ & 28,544 & 0.72 \\
\hline
\end{tabular}

ELSI-sf, Economic Standard of Living Index-short form; MET, metabolic equivalent to tasks.

It was found that $80 \%$ of the participants were born in New Zealand; however, only $2 \%$ of these identified themselves as Māori. In the Canterbury region, 7\% of the population identifies as being of Māori descent [40]. The lower population in this study may reflect that Māori populations are more likely to present for colonoscopy with significant "red flag" symptoms [41] and therefore were pre-emptively excluded from participation in this study.

There are few studies of FGIDs in the New Zealand population. As is common in the FGID literature, a range of diagnostic criteria have been used in these studies, making comparison with the COMFORT cohort difficult. Previous New Zealand FGID studies have suggested IBS prevalence of around 20\% [42-45]. More recently, a Rome Foundation Working Team reported that the prevalence of IBS in New Zealand (pooled with North America, Europe, and Australia) is $8 \%$ (with a $95 \%$ confidence interval for 7.0-8.3) [39]. It is likely that differences between countries in the prevalence of FGIDs may reflect cultural differences and variability in health care that lead to reporting differences between countries $[39,46]$.

The incidence of IBS is greatest in those aged $<50$ years $[47,48]$, with the majority of patients first reporting IBS symptoms before 35 years of age $[6,47]$. The mean age of IBS participants in the COMFORT cohort was 51.5 years, reflecting the method of recruitment for the COMFORT cohort that focussed on those attending for colonoscopy to obtain a range of biological samples not otherwise available. However, this increased age is consistent with other IBS cohorts recruited internationally which report mean ages closer to 50 years $[49,50]$. The Rome Foundation Working Team also reported that the mean age in their large-scale meta-analysis was 40 years [39]. It has been suggested that IBS symptoms can potentially remit over time, particularly in patients over 50 [6]. However, while abdominal pain has been reported to be milder in patients over 50 , they were reported to have a worse quality of life [5].

There was a female predominance in the COMFORT study (70\% female overall), which extended to each FGID phenotype in the case group ranging from 93.3 to $71.4 \%$; the control group, while still demonstrating a female predominance, was closer to a 50/50 gender distribution (55.8\% female). The female predominance of patients with IBS is well documented $[49,51,52]$. Historically, this was thought to be due to a level of neuroticism in the female patient population [49]; however, it has been demonstrated that there is no difference in health care seeking between male and female patients with IBS [47, 53, 54]. It has also been suggested that female specific sex hormones are associated with the female predominance in IBS symptoms; however, the mechanisms behind this are currently unknown $[55,56]$. Genetics (and associated immune activation) are also potential predisposing factors in the pathophysiology of IBS in women [57].

The levels of educational achievement in the COMFORT cohort, of which $86 \%$ achieved at least one high school qualification and $46 \%$ a bachelor's degree or higher, are higher than that of the New Zealand population in 2015 of 77 and $30 \%$, respectively [58]. However, similarly high education levels were found in an IBS study performed in the United States in 2018, where 28\% of the study population had gained a postgraduate qualification [59] compared with $23 \%$ in the COMFORT study.

Around $80 \%$ of the participants of the COMFORT study had engaged in some form of cardiovascular exercise in the 2 weeks before participation. This is a greater proportion than the general New Zealand population, around half of which (51\%) engaged in physical activity 
[60]. However, consistent with the findings from the COMFORT cohort, an Australian FGID cohort reported that at least $70 \%$ of their IBS participants had performed some exercise in the last 2 weeks [52].

Economic living standards in the COMFORT cohort are higher than that of the New Zealand population with $90 \%$ of the COMFORT cohort in the top four (less deprived) ELSI-sflevels "Fairly Comfortable" to "Very Good" compared with $76 \%$ in the general New Zealand population [30]; within the COMFORT study, $87 \%$ of the cohort fell between the top 3 levels (Comfortable, Good, and Very Good), 12, 40, and 35\%, respectively, compared with $61 \%$ $(22,29$, and $10 \%$, respectively) in the New Zealand population. Furthermore, COMFORT participants are 3 times more likely to score the top ELSI-sf level of "Very Good" (30.5\% in the COMFORT cohort compared with $10 \%$ in the general population) [30]. There is conflicting evidence about the association of IBS symptoms with socioeconomic status (SES), with evidence existing for association with lower SES $[47,61]$ and higher SES [62-64], particularly during childhood. However, this observation may also reflect the older age of the COMFORT cohort and also that those who present for health care such as colonoscopy [43], or volunteer for research may be more likely to come from groups with higher living standards [65].

Alcohol consumption among participants in the COMFORT study (79\%) was the same as New Zealand national rates for alcohol consumption in people aged 15 years and older [66] and similar to an Australian FGID study in which at least $70 \%$ of the cohort drank alcohol [52]. Perceived alcohol intolerance in IBS patients has been reported to be between 12 and $17 \%[67,68]$, and there is some limited mechanistic evidence for the effect of alcohol in worsening IBS symptoms [69]. Mechanistic evidence for the effect of smoking on IBS symptoms, however, is lacking. Having ever smoked cigarettes (defined as greater than 100 cigarettes over a lifetime) was reported by $37.4 \%$ COMFORT study participants, and of those who had ever smoked only $11.9 \%$ (4.5\% of the total cohort) were current smokers at recruitment. This is lower than an Australian FGID study in which a similar proportion of participants had smoked in the past (40\%), but $11 \%$ reported they still smoke [52]. It is also lower than current New Zealand smoking rates of 16\% [70]. Current literature does not support an association between smoking status and IBS symptoms [71, 72].

The baseline demographics of the COMFORT study participants are broadly comparable with other IBS cohorts and the general population. Differences were found between participants recruited from endoscopy lists and from the general public, where the participants from the general public were younger, smoked, and drank less and a higher proportion of participants had attained postgraduate degrees. As these participants volunteered for the study rather than being invited, these differences were expected as, typically, individuals who volunteer for research are more health conscious than the general public $[43,65]$. There was no significant difference between these 2 groups in the diagnosis type, exercise level, ELSIsf scores, and the female predominance of participants was maintained in both groups. However, future analyses will adjust for possible confounding effects including age, sex, living standard, and smoking status.

Limitations of the dataset collected as part of the COMFORT cohort include the incomplete nature of many of the biological sample datasets. Furthermore, the participants who did not undergo colonoscopy may have had diagnoses other than FGIDs. However, these diagnoses had been made by the general practitioner. Many of the patients will have had a colonoscopy previously or have had non-invasive investigations for other diagnoses (e.g., coeliac disease and inflammatory bowel disease). In the future, subgroup analysis will need to be performed with and without these participants being included.

While the integration of the clinical, dietary, and biological data collected from participants in the COMFORT study has not been presented here, future analyses have been planned. These include the processing of biological samples collected from this cohort (blood, breath, urine, stool, and colonic mucosa tissue) to investigate differences in host-microbiome interactions by measuring faecal composition and predictive functions using shot-gun metagenomics, the faecal, plasma, and urine metabolomes, and host genetics between COMFORT cases and controls. The dietary variables with associated symptoms captured in the FAST diary will be analyzed to determine the role of food groups and specific foods in the genesis of GI symptoms in the COMFORT cohort. Clinical data including medical history and medication use, as well as immediate, current, and chronic GI symptoms, psychological and quality of life data, as well as the baseline demographic data discussed above will be integrated with the results of the biological and dietary data as it becomes available.

In conclusion, the COMFORT cohort is a unique resource that will enable a systems biology approach to be taken to understanding the aetiology and pathogenesis of FGID, particularly IBS, FC, and FD. The cohort is broadly comparable with other IBS cohorts and the general population and will be used independently and collaboratively to further our understanding of FGIDs. 


\section{Acknowledgements}

The research team would like to acknowledge the research participants, endoscopy clinic staff, and administrators for their assistance in recruiting for this study.

\section{Statement of Ethics}

This study has been conducted in accordance with the protocol, International Conference on Harmonization (ICH) guidelines, applicable national and local requirements, and the ethical principles that have their origin in the Declaration of Helsinki. The COMFORT study protocol was reviewed by the Northern A ethics committee who granted approval (Ref16/NTA/21) as well as the amendment to protocol approved on August 15, 2017. All study participants in the COMFORT study entered the study on a voluntary basis and were able to withdraw from the study at any time with no impact on the standard of their health care. Participant anonymity is respected and protected by password-protected data management systems.

\section{Conflict of Interest Statement}

The authors declare no conflicts of interest.

\section{Funding Sources}

COMFORT is a part of the Healthy Digestion Research Priority Programme of the High-Value Nutrition National Science Challenge funded by the Ministry of Business, Innovation and Employment in New Zealand. The study team is based out of the University of Otago, Department of Medicine, Christchurch, New Zealand.

\section{Author Contributions}

R.G., N.R., N.T., P.S., K.F., J.C., W.Y., and J.K. conceived and designed the study and analyses. R.G. obtained ethical approval. P.H., S.S., and R.C. collected the data. P.H., R.C., and S.B. performed the analysis. P.H. and R.C. wrote the manuscript. S.S., J.K., S.B., W.Y., J.C., K.F., P.S., N.T., N.R., and R.G. gave critical feedback on the manuscript.

\section{References}

1 Drossman DA. Functional gastrointestinal disorders: history, pathophysiology, clinical features and Rome IV. Gastroenterology. 2016;150(6):1262-79.e2.

2 Buono JL, Carson RT, Flores NM. Health-related quality of life, work productivity, and indirect costs among patients with irritable bowel syndrome with diarrhea. Health Qual Life Outcomes. 2017;15(1):35.

3 Hahn BA, Kirchdoerfer LJ, Fullerton S, E Mayer therapeutics . Patient-perceived severity of irritable bowel syndrome in relation to symptoms, health resource utilization and quality of life. Aliment Pharmacol Ther. 1997; 11(3):553-9.

4 Hahn BA, Yan S, Strassels S. Impact of irritable bowel syndrome on quality of life and resource use in the United States and United Kingdom, Digestion. 1999;60(1):77-81

5 Tang YR, Yang WW, Liang ML, Xu XY, Wang MF, Lin L. Age-related symptom and life quality changes in women with irritable bowel syndrome. World J Gastroenterol. 2012; 18(48):7175-83.

6 Canavan C, West J, Card T. The epidemiology of irritable bowel syndrome. Clin Epidemiol. 2014;6:71-80.

7 Lovell RM, Ford AC. Global prevalence of and risk factors for irritable bowel syndrome: a meta-analysis. Clin Gastroenterol Hepatol. 2012;10(7):712-e4.

8 Mearin F, Balboa A, Badía X, Baró E, Caldwell $\mathrm{E}$, Cucala $\mathrm{M}$, et al. Irritable bowel syndrome subtypes according to bowel habit: revisiting the alternating subtype. Eur J Gastroenterol Hepatol. 2003;15(2):165-72.
9 Camilleri M, Halawi H, I Oduyebo, hepatology . Biomarkers as a diagnostic tool for irritable bowel syndrome: where are we? Expert Rev Gastroenterol Hepatol. 2017;11(4):30316.

10 Khlevner J, Park Y, Margolis KG. Brain-gut axis: clinical implications. Gastroenterol Clin North Am. 2018;47(4):727-39.

11 Quigley EMM. The gut-brain axis and the microbiome: clues to pathophysiology and opportunities for novel management strategies in irritable bowel syndrome (IBS). J Clin Med. 2018;7(1):6

12 Barbara G, Feinle-Bisset C, Ghoshal UC, Quigley EM, Santos J, Vanner S, et al. The intestinal microenvironment and functional gastrointestinal disorders. Gastroenterology. 2016;150:1305-18.

13 Ng QX, Soh AYS, Loke W, Lim DY, Yeo WS. The role of inflammation in irritable bowel syndrome (IBS). J Inflamm Res. 2018;11:345-9.

14 Bashashati M, Moossavi S, Cremon C, Barbaro MR, Moraveji S, Talmon G, et al. Colonic immune cells in irritable bowel syndrome: a systematic review and meta-analysis. Neurogastroenterol Motil. 2018;30(1): e13192.

15 Chassard C, Dapoigny M, Scott KP, Crouzet L, Del'homme C, Marquet P, et al. Functional dysbiosis within the gut microbiota of patients with constipated-irritable bowel syndrome. Aliment Pharmacol Ther. 2012;35(7): 828-38.

16 González-Castro AM, Martínez C, SalvoRomero E, Fortea M, Pardo-Camacho C, Pérez-Berezo T, et al. Mucosal pathobiology and molecular signature of epithelial barrier dysfunction in the small intestine in irritable bowel syndrome. Eur J Gastroenterol Hepatol. 2017;32(1):53-63.

17 Windgassen S, Moss-Morris R, Everitt H, Sibelli A, Goldsmith K, Chalder T. Cognitive and behavioral differences between subtypes in refractory irritable bowel syndrome. Behav Ther. 2018;50(3):594-607.

18 Zhu X, Han Y, Du J, Liu R, Jin K, Yi W. Microbiota-gut-brain axis and the central nervous system. Oncotarget. 2017;8(32):5382938.

19 Pellissier S, Bonaz B. The place of stress and emotions in the irritable bowel syndrome. Vitamins and hormones. 2017;103:327-54.

20 Bijkerk CJ, Muris JW, Knottnerus JA, Hoes AW, De Wit NJ. Systematic review: the role of different types of fibre in the treatment of irritable bowel syndrome. Aliment Pharmacol Ther. 2004;19(3):245-51.

21 Defrees DN, Bailey J. Irritable bowel syndrome: epidemiology, pathophysiology, diagnosis, and treatment. Prim Care. 2017;44(4): 655-71.

22 Flik CE, Bakker L, Laan W, van Rood YR, Smout AJ, de Wit NJ. Systematic review: the placebo effect of psychological interventions in the treatment of irritable bowel syndrome. World J Gastroenterol. 2017;23(12):2223-33.

23 Ruepert L, Quartero AO, de Wit NJ, van der Heijden GJ, Rubin G, Muris JW. Bulking agents, antispasmodics and antidepressants for the treatment of irritable bowel syndrome. Cochrane Database Syst Rev. 2011;(8): CD003460. 
24 Sánchez B, Delgado S, Blanco-Míguez A, Lourenço A, Gueimonde M, A Margolles, et al. Probiotics, gut microbiota, and their influence on host health and disease. Mol Nutr Food Res. 2017;61(1):1600240.

25 Koloski NA, Jones M, Talley NJ. Evidence that independent gut-to-brain and brain-togut pathways operate in the irritable bowel syndrome and functional dyspepsia: a 1-year population-based prospective study. Aliment Pharmacol Ther. 2016;44(6):592-600.

26 Palsson OS, Whitehead WE, van Tilburg MAL, Chang L, Chey W, Crowell MD, et al. Development and validation of the Rome IV diagnostic questionnaire for adults. Gastroenterology. 2016;150(6):1481-91.

27 Ware JE, Keller SD, Kosinski M. SF-12: how to score the SF-12 physical and mental health summary scales. Boston, MA: Health Institute, New England Medical Center; 1995.

28 Snaith RP, Zigmond AS. The hospital anxiety and depression scale. Br Med J. 1983; 292(6516):344-70

29 Koloski NA, Jones M, Hammer J, von Wulffen M, Shah A, Hoelz H, et al. The validity of a new Structured Assessment of Gastrointestinal Symptoms Scale (SAGIS) for evaluating symptoms in the clinical setting. Dig Dis Sci. 2017;62(8):1913-22.

30 Jensen J, Spittal M, Krishnan V. ELSI short form: user manual for a direct measure of living standards. New Zealand: Ministry of Social Development Wellington; 2005.

31 Reeve BB, Hays RD, Bjorner JB, Cook KF, Crane PK, Teresi JA, et al. Psychometric evaluation and calibration of health-related quality of life item banks: plans for the PatientReported Outcomes Measurement Information System (PROMIS). Med Care. 2007;45(5 Suppl 1):S22-31.

32 Spiegel BM, Hays RD, Bolus R, Melmed GY, Chang L, Whitman C, et al. Development of the NIH patient-reported outcomes measurement information system (PROMIS) gastrointestinal symptom scales. Am J Gastroenterol. 2014;109(11):1804-14.

33 Khanna D, Hays RD, Shreiner AB, Melmed GY, Chang L, Khanna PP, et al. Responsiveness to change and minimally important differences of the patient-reported outcomes measurement information system gastrointestinal symptoms scales. Dig Dis Sci. 2017; 62(5):1186-92.

34 Wright-McNaughton M, Ten Bokkel Huinink S, Frampton C, McCombie A, Talley N, Skidmore $\mathrm{P}$, et al. Measuring Diet Intake and Gastrointestinal Symptoms in Irritable Bowel Syndrome: Validation of the Food and Symptom Times Diary. Clin Transl Gastroenterol. 2019;10(12):e00103.

35 GE Healthcare Life Sciences. Isolation of mononuclear cells methology and applications. 1983.
36 Mesko B, Poliska S, Szegedi A, Szekanecz Z, Palatka K, Papp M, et al. Peripheral blood gene expression patterns discriminate among chronic inflammatory diseases and healthy controls and identify novel targets, BMC Med Genomics. 2010;3(1):15.

37 Statistics ABo. Australian health Survey. Canberra: Australian Bureau of Statistics; 2007. p. 55-73.

38 Talley NJ, Gabriel SE, Harmsen WS, Zinsmeister AR, Evans RW. Medical costs in community subjects with irritable bowel syndrome. Gastroenterology. 1995;109(6):1736-41.

39 Sperber AD, Dumitrascu D, Fukudo S, Gerson C, Ghoshal UC, Gwee KA, et al. The global prevalence of IBS in adults remains elusive due to the heterogeneity of studies: a Rome Foundation working team literature review. Gut. 2017;66(6):1075-82.

40 Aotearoa SNT. 2013 Census QuickStats about a place: Canterbury Region: Stats NZ Tatauranga Aotearoa; 2013. Available from: http:// archive.stats.govt.nz/Census/2013-census/ profile-and-summary-reports/quickstatsabout-a-place.aspx? request_value $=14703 \&$ tabname $=$.

41 Sammour T, Kahokehr A, Vather, R, Connolly $A B$, Hill AG. Ethnic disparity in colonic cancer outcomes in New Zealand: biology or an access issue? Colorectal Dis. 2009;12(7 Online):e50-6.

42 Barbezat G, Poulton R, Milne B, Howell S, Fawcett JP, Talley N. Prevalence and correlates of irritable bowel symptoms in a New Zealand birth cohort. N Z Med J. 2002; 115(1164):U220.

43 Wyeth JW. Functional gastrointestinal disorders in New Zealand. J Gastroenterol Hepatol. 2011;26(S3):15-8.

44 Welch GW, Pomare EW. Functional gastrointestinal symptoms in a Wellington Community sample. N Z Med J. 1990;103(897): 418-20.

45 Spencer R, Gearry R, Pearson J, Skidmore P. Relationship between fructose and lactose intakes and functional gastrointestinal symptoms in a sample of 50-year-old Cantabrians in New Zealand. N Z Med J. 2014;127(1406): 39-47.

46 Sperber AD, Gwee KA, Hungin AP, Corazziari E, Fukudo S, Gerson C, et al. Conducting multinational, cross-cultural research in the functional gastrointestinal disorders: issues and recommendations. A Rome Foundation working team report. Aliment Pharmacol Ther. 2014;40(9):1094-102.

47 Drossman DA, Li Z, Andruzzi E, Temple RD, Talley NJ, Thompson WG, et al. U.S. householder survey of functional gastrointestinal disorders. Prevalence, sociodemography, and health impact. Dig Dis Sci. 1993;38(9):1569-80.

48 Minocha A, Johnson WD, Abell TL, Wigington WC. Prevalence, sociodemography, and quality of life of older versus younger patients with irritable bowel syndrome: a populationbased study. Dig Dis Sci. 2006;51(3):446-53.
49 Lee OY, Mayer EA, Schmulson M, Chang L, Naliboff B. Gender-related differences in IBS symptoms. Am J Gastroenterol. 2001;96(7): 2184-93.

50 Lee YT, Hu LY, Shen CC, Huang MW, Tsai SJ, Yang AC, et al. Risk of psychiatric disorders following irritable bowel syndrome: a nationwide population-based cohort study. PLoS One. 2015;10(7):e0133283.

51 Dong YY, Zuo XL, Li CQ, Yu YB, Zhao QJ, Li YQ. Prevalence of irritable bowel syndrome in Chinese college and university students assessed using Rome III criteria. World J Gastroenterol. 2010;16(33):4221-6.

52 Koloski NA, Jones M, Young M, Talley NJ. Differentiation of functional constipation and constipation predominant irritable bowel syndrome based on Rome III criteria: a population-based study. Aliment Pharmacol Ther. 2015;41(9):856-66.

53 Talley NI, Zinsmeister AR, Melton LJ III. Irritable bowel syndrome in a community: symptom subgroups, risk factors, and health care utilization. Am J Epidemiol. 1995; 142(1): 76-83.

54 Gudleski GD, Satchidanand N, Dunlap LJ, Tahiliani V, Li X, Keefer L, et al. Predictors of medical and mental health care use in patients with irritable bowel syndrome in the United States. Behav Res Ther. 2017;88:65-75.

55 Icenhour A, Witt ST, Elsenbruch S, Lowén M, Engström M, Tillisch K, et al. Brain functional connectivity is associated with visceral sensitivity in women with irritable bowel syndrome. Neuroimage Clin. 2017;15:449-57.

56 Bhatt RR, Gupta A, Labus JS, Zeltzer LK, Tsao JC, Shulman RJ, et al. Altered brain structure and functional connectivity and its relation to pain perception in girls with irritable bowel syndrome. Psychosom Med. 2019;81(2):14654.

57 Houghton LA, Heitkemper, M, Crowell M, Emmanuel A, Halpert A, McRoberts JA, et al. Age, gender and women's health and the patient. Gastroenterology. 2016;150(6):133243.

58 Stats NZ Tatauranga Aotearoa. Adult Educational Attainment 2015. 2016 Jul. Available from: http://archive.stats.govt.nz/browse_ for_stats/snapshots-of-nz/nz-progress-indicators/Home/Social/adult-educational-attainment.aspx.

59 Farhadi A, Banton D, Keefer L. Connecting our gut feeling and how our gut feels: the role of well-being attributes in irritable bowel syndrome. J Neurogastroenterol Motil. 2018; 24(2):289-98.

60 Ministry of Health W, New Zealand. Activity levels in New Zealand Wellington. 2016 [cited 2016 Aug 30]. Available from: https://www. health.govt.nz/your-health/healthy-living/ food-activity-and-sleep/physical-activity/activity-levels-new-zealand. 
61 Marmot M, Goldblatt P, Allen J, Bell R, Bloomer E, Donkin A, et al. Review of social determinants and the health divide in the WHO European Region: final report: World Health Organisation; 2014.

62 Howell S, Talley NJ, Quine S, Poulton R. The irritable bowel syndrome has origins in the childhood socioeconomic environment. Am J Gastroenterol. 2004;99(8):1572-8.

63 Grodzinsky E, Hallert C, Faresjö T, Bergfors E, Faresjö AO. Could gastrointestinal disorders differ in two close but divergent social environments? Int J Health Geogr. 2012; 11(5):5.

64 Gwee KA. Irritable bowel syndrome in developing countries: a disorder of civilization or colonization? Neurogastroenterol Motil. 2005;17(3):317-24.
65 Søgaard AJ, Selmer R, Bjertness E, Thelle D. The Oslo Health Study: the impact of self-selection in a large, population-based survey. Int J Equity Health. 2004;3(1):3.

66 Alcohol.org.nz. New Zealand drinking patterns. 2018. Available from: https://www.alcohol.org.nz/resources-research/facts-andstatistics/nz-statistics/new-zealand-drinking-patterns.

67 Simrén M, Månsson A, Langkilde AM, Svedlund, J, Abrahamsson $\mathrm{H}$, Bengtsson U, et al. Food-related gastrointestinal symptoms in the irritable bowel syndrome. Digestion. 2001;63(2):108-15.

68 Halder SL III, Locke GR, Schleck CD, Zinsmeister AR, Talley NJ. Influence of alcohol consumption on IBS and dyspepsia. Neurogastroenterol Motil. 2006;18(11):1001-8.
69 Reding KW, Cain KC, Jarrett ME, Eugenio MD, Heitkemper MM. Relationship between patterns of alcohol consumption and gastrointestinal symptoms among patients with irritable bowel syndrome. Am J Gastroenterol. 2013;108(2):270-6.

70 Smokefree New Zealand. Facts and Figures. 2016 April 20. Available from: https://www. smokefree.org.nz/smoking-its-effects/factsfigures.

71 Chatila R, Merhi M, Hariri E, Sabbah N, Deeb ME. Irritable bowel syndrome: prevalence, risk factors in an adult Lebanese population. BMC Gastroenterol. 2017;17(1):137.

72 Sirri L, Grandi S, Tossani E. Smoking in irritable bowel syndrome: a systematic review. J Dual Diagn. 2017;13(3):184-200. 